\title{
Da palavra amor ao amor da palavra: a palavra contra o desejo em Fantasia e avesso de Arriete Vilela
}

\author{
Roberto Sarmento Lima \\ Professor Adjunto 2, doutor em Literatura \\ Brasileira, lotado na Faculdade de Letras, da \\ Universidade Federal de Alagoas, atuando tanto \\ na graduação quanto no programa de pós- \\ graduação em letras e linguistica.
}

Resumo: Análise do livro de poemas em prosa de Arriete Vilela Fantasia e avesso, cujo objeto é a dramatização da palavra na modernidade como instrumento que recusa a comunicação em prol de uma busca da autonomia de si mesma, com base numa teoria do poético e numa visão filosófica materialista que relaciona a pretensa pureza do ato literário com as imposiçōes ideológicas do discurso.

Résumé: Analyse du livre de poèmes en prose de Arriete Vilela Fantasia e avesso, dont l'objet est la dramatisation du mot dans la modernité en tant qu'instrument qui refuse la communication en faveur d'une recherche de l'autonomie de soimême, ayant pour base une théorie du poétique et une vision philosophique matérialiste qui met en rapport la supposée pureté de l'acte littéraire et les contraintes idéologiques du discours.

Palavras-chave: modernidade; poesia; ideologia; circularidade; silêncio

Mots-clé: modernité; poesie; idéologie; circulaireté; silence 



\section{Introdução}

O leitor de "Fantasia e Avesso", de Arriete Vilela, depara, logo na primeira página, com a concepção de literatura que a autora tenta subliminarmente exprimir:

A fantasia, amor, o avesso dos fatos, a realidade fibrosa, a palavra à espera (p. 13).

A fantasia - terreno do imaginário - , para se fazer texto, precisa da palavra, que está "à espera", pronta para pronunciar e realizar o desejo. A palavra é o suporte do sonho. Mundo estranho o do sonho que só se completa, só se dá à compreensão, se cair no mundo logocêntrico!

A palavra, despojada e oculta, transmudando o castanho da vida; a palavra, atitude permanente, ímpeto precioso e desordenado, gracioso e alegre. A palavra: gangorra e fantasia, significação na tessitura da alma (p. 13).

Imediatamente vejo instalar-se a construção do conflito entre a fantasia e a palavra, seu necessário amparo: fantasia e avesso. $\mathrm{O}$ ato de dizer a fantasia, pela palavra, é matar - no sentido de que a fantasia é fugaz e, por isso, tem fim - a própria fantasia, que, para se realizar como "tessitura"/textura, para existir enquanto texto literário, recorre a um instrumento ontologicamente alheio a si mesma: a palavra. Daí a fantasia ser "o avesso dos fatos", o avesso da "palavra à espera". Pronunciar a fantasia: o preço que a fantasia paga para, perdendo-se a si mesma, transformar-se em texto literário.

A fantasia tem sido estudada como copartícipe do terreno das emoções e do desejo, oposta a qualquer verbalização. Comparada ao estado mítico, é a palavra primeira, fundante do psiquismo humano, contendo a sua própria lógica. Tentar sua tradução, por meio do signo verbal, é retirar-lhe a força originária e fazê-la conviver com o chamado princípio de realidade, representado aqui pela palavra, que, por definição, é lugar da ideologia e 
das marcas sociais; é conhecimento e compreensão do mundo. Levar a fantasia à palavra é algo parecido com a satisfação amorosa carnal, a "petite mort" com que os franceses designam o orgasmo - misto de vida e morte no momento de sua realização.

\section{Fantasia mas avesso?}

A palavra, como esclarece Mikhail Bakhtin (1981), é o signo ideológico por excelência, porquanto, produto cultural, vem carregada das impressões que o mundo cotidiano, das relações intersubjetivas - verificáveis mormente na área do trabalho - imprime à linguagem enquanto mediação dessas relações sociais. Portanto, a palavra não é um em si, mas sempre remete a algo que vem de fora, precisamente às situações de tensão compreendidas no âmbito das relações de produção. As concepções idealistas da linguagem é que têm desviado o foco do problema, fazendo crer que o nascedouro da ideologia (con $\neg$ cepções de mundo) é a consciência individual. Seria próprio da consciên-cia autoproduzir-se comoum certo organismo biológico o faz pela partenogênese? Ou, ao contrário, para exprimir-se - como também para fazer-se - , precisaria de uma realidade material, de uma realidade semiótica comum aos participantes da interação verbal? Como, por exemplo, ter acesso à consciência senão por meio de uma expressão cultural, uma vez que o homem só pensa culturalmente, nunca abstraí $\neg$ do do meio em que vive? Assim, uma manifestação afetiva só pode ser compreendida por um gesto, por uma expressão facial, por uma palavra. A fantasia, igualmente, só pode ser lida tomando como base uma semiotização (não necessariamente, ou unicamente, ou totalitariamente por intermédio da palavra), de um suporte cujas formas de divulgação sejam coerentes com o mercado de circulação dos signos.

\footnotetext{
"A palavra: gangorra e fantasia" - eis a equação que permite situar a natureza dessa questão. Estaria Arriete Vilela refletindo sobre o dilema de viver a fantasia, mas também de exprimi-la sob o risco de vê-la perder-se nos desvãos da consciência?
} 
A fantasia é o avesso da palavra, assim como a palavra é o avesso da fantasia:

A fantasia, amor. O avesso da palavra que crepita e que é êxtase silencioso e secreto (p. 14).

Entretanto, palavra e fantasia não se separam. Não quero com isso dizer que a palavra deva substituir a fantasia, a experiência viva e intransferível da fantasia. Toda a cultura do Ocidente vive sob o império do logocentrismo, o que faz com que todo ato simbólico seja revertido em ato linguístico. As representações não verbais têm, no entanto, certa autonomia, isto é, certa especificidade, não sendo, pois, inteiramente substituídas por palavras. "É impossível, em última análise, exprimir em palavras, de modo adequado, uma composição musical ou uma representação pictórica" (BAKHTIN, 1981, p. 38). O que implica dizer, de outra forma, que a tradução fiel entre os diversos tipos de linguagens não é uma realidade confirmada na prática. Simplesmente, a palavra acompanha o signo não verbal, co $\neg$ mentando-o, acrescentando-lhe informações. Ainda segundo Bakhtin, "a palavra está presente em todos os atos de compreensão e em todos os atos de interpretação" (ibidem).

A fantasia, por si só, já é uma interpretação. O sonho não é, ele mesmo, um texto? A leitura do sonho - a interpretação da interpretação — não é a destruição desse sonho? ${ }^{1}$ No entanto, para que o sonho seja texto literário, é transformado em texto verbal. Fantasia e avesso? Ou fantasia mas avesso?

Eu te quero prescindindo de uma realidade que passa a ser comum quando não tem avesso. De novo a palavra: mergulho e fôlego, um desafio. (p. 19)

Arriete Vilela experimenta a vigilância da palavra, a perseguição da palavra, que insiste em romper a fantasia ela mesma. Esse confron $\neg$ to lembra muito bem o duelo verificado entre o mito e o logos: o mito, interpretação
${ }^{1}$ A esse respeito, há certa ambiguidade, segundo Flávio Kothe (cf. "Hermenêutica literária e psicanalítica", in Kothe, Literatura e sistemas intersemióticos, São Paulo, Cortez \& Autores Associa $\neg$ dos, 1981, p. 225), no título original alemão da obra máxima de Freud, Die traumdeutung, que, em tradução vernácula, desfaz a duplicidade de sentido. O sintagma "interpretação dos sonhos" indica clara-mente que os sonhos são interpretáveis, mas apenas isso. $\mathrm{O}$ título alemão, ao contrário, por estar no singular, sugere que o sonho, além de interpretável, é, por si só, uma interpretação. Nesse caso, ratifica-se a premissa de Bakhtin segundo a qual o código nâo verbal tem um sentido e uma manifestação semiótica que não precisam necessariamente ser traduzidos por signos verbais. 
2 Essa dissociação entre a poesia e a sociedade é, inclusive, uma prática legitimada pelo discurso oficial da disciplina Teoria da Litera $\neg$ tura, divulgada sobretudo nos meios universitários, onde se produz o chamado discurso competente. A disseminação desse ponto de vista pela crítica textualista via estruturalismo, neoestruturalismo, new criticism etc. - tem obscurecido as reais ligações entre o texto literário e o mundo do trabalho, ingenuizando o ato de escrever. afetiva da realidade; o logos, a sua explicação racional. A poesia é, originariamente, da ordem das cenestesias; e a boa poesia é aquela que consegue, segundo Bachelard, provocar no leitor o estado cenestésico experienciado ou criado pelo poeta. Além de tudo, a poesia é uma linguagem fundante: na aurora do homem, ela representou uma via de conhecimento do mundo, algo só possível em virtude das precárias condições das técnicas de trabalho. Naquele instante, a mão e o pensamento ainda não tinham sofrido a separação que a divisão social do trabalho mais tarde imporia à economia. Na comunidade primitiva produzia-se o que se consumia; a economia era de troca e subsistência. A troca, então mediatizada pelo dinheiro, só se deu com a sofisticação do trabalho e com a artificialização da separação entre a produção de instrumentos e a produção de ideias. O dinheiro é, assim, o primeiro símbolo de uma sociedade já em condições de abstrair e criar teorias filosóficas, razão de terem ambos - o aparecimento do dinheiro e da filosofia - coincidido historicamente, pois o que é o dinheiro senão também uma abstração, com que é representado o trabalho abstrato?

\section{Poesia e trabalho}

Na sociedade mítica, o trabalho real, concreto, efetivo, dependia da união dos homens em coletividade; e, ainda assim, o domínio sobre a natureza era precário. $\mathrm{O}$ recurso à magia preenchia a ausência de uma técnica de trabalho que garantisse ao homem sua sobreviᄀvência, de forma que, na sua origem, a fantasia não tinha um caráter meramente lúdico, mas era uma forma de trabalho (THOMSON, 1977). A dança, a música e, posteriormente, a poesia eram manifestações culturais que valiam sobretudo pela sua força social. Dissociar - como hoje se faz - a poesia da sociedade ${ }^{2}$ é cometer uma violência simbólica e reificar o imaginário, jogando-o no terreno da gratuidade, o que faz perder o liame que une a produção literária à produção material. Nesse âmbito, o esteticismo fin $d u$ siècle representou a mais alta manifestação e ilustração dessa concepção de arte, o paroxismo a que chegou a arte 
no contexto da sociedade industrial, voltada mais para o consumo rápido e para o imediatismo do lucro.

Por isso - por causa das mudanças verificadas na base econômica da sociedade - é que não se pode definir de uma vez por todas o ser literário. Tal atitude seria privilegiar a visão estática da história. O desejo, o amor, o devaneio também têm um percurso social; a língua, a expressão artística acompanham as tendências da sociedade. A literatura, hoje, cada vez mais separada do fazer social, exibe sua matéria, instaurando uma crítica interna - ao mesmo tempo que, pela recusa do discurso concatenado, critica a sua articulação com a realidade. O resultado é uma fragmentação linguística, com espaços em branco, lacunas, ausências (de nexos e ligações sintáticas):

o mundo e as coisas, borboleta marrom, aranha caída no vermelho da flor, baba peçonhenta. Pétalas negras molhadas no sangue doce. Ah, o avesso da singularidade de tudo o que me chegava através de uma hemorrágica paixão. $\mathrm{O}$ avesso da libertação torturada na asa quebrada do pássaro selvagem. A dor do golpe dado às costas, a dor da perda. (p. 26)

Trata-se, como se pode verificar no excerto acima, de um efeito estilístico procurado conscientemente segundo uma discursividade moderna de que lança mão a autora para representar uma aparente situação caótica, não linear. Na verdade, essa crise entre a linguagem e a realidade é o recurso poético que Arriete Vilela utilizou para "evidenciar" a inadequação da palavra à vivência da paixão. Ou seja: a paixẫo nâo pode ser descrita; pode apenas - e isso é uma exigência do texto que tenta cifrar a paixão - fazer-se imagem, figura, sinestesia. A paixão, assim, transforma-se em palavra, artifício que traduz a submissão da paixão à palavra que, embora precária, a representa. Os sentimentos são, com efeito, pré-verbais, por serem preconceptuais; mas só se dão a conhecer, em nível consciente, pela palavra. 
${ }^{3} \mathrm{O}$ discurso que converge para si mesmo, tematizando a si próprio e não a outro referente, termina por cair no solipsismo. No caso dos poemas em prosa de Arriete Vilela, percebe-se uma direção nesse sentido: são poemas que se remetem a si mesmos, através de uma paráfrase intratextual. Chamei de discurso em repouso a consequência desse processo: falando de si mesmo, o discurso não evolui nem instaura uma autocrítica, mas recolhe-se ingenuamente à sua especifi $\neg$ cidade enquanto discurso particular. (Cf. Affonso Romano de Sant'Anna, Paródia, paráfrase \& cia., São Paulo, Ática, 1985. p. 27-28).

\section{Poesia e circularidade}

Arriete Vilela, em todo o seu texto - dez poemas em prosa -, guia-se pelo princípio da circularidade. cada poema é o espelho do outro, a ponto de o discurso convergir para o silêncio. Poesia é som, mas a repetição do mesmo som (e, no caso, repetição dos mesmos significados) conduz à morte do discurso, ao silêncio. O que aqui chamo de circularidade é o que se pode chamar também de paráfrase, um discurso em repouso. ${ }^{3}$ Os poemas são, assim, mutuamente implicantes, como denuncia o início de Fantasia e Avesso III:

...e retomado. Noutros termos, bem sabemos. Qual asa quebrada do pássaro selvagem. (p. 25; grifo meu)

Ou Fantasia e Avesso V:

Retomado.,. Na ronda que fazes à minha paixão. No brinde a esse amor, forte como um cordão umbilical. (p. 37; grifo meu)

Ou, ainda, Fantasia e Avesso VI:

... mas me avessa sobretudo para as tuas grandes compreensões. A emoção boiando nos nossos olhos coagulados de flores vermelhas. (p. 43)

Com isso, finge-se desconhecer o ritmo do tempo, decompondo objetos e articulando os pedaços sem obedecer a uma ordem prevista. Ao lado do princípio da circularidade, combina-se o princípio de decomposição, próprio da lírica moderna (FRIEDRICH, 1978, p. 55), que se dá em associações intencionalmente dirigidas à ruptura comunicativa, isto é, a um estado de tensão entre o dizer e o sentir, de modo a tornar mais opaca a palavra poética. $\mathrm{O}$ resultado é sempre, como já coloquei, um discurso circular, parafrásico de si mesmo, intratextual, autocentrado, falho de intenção comunicacional. Como diz a própria autora: 
O fio da meada perdido nas decifrações paralelas.

$\mathrm{O}$ fio da meada retomado nas entrelinhas. Ah, a fantasia das entrelinhas! (p. 44; grifos meus)

Talescritura vincula-se, ao menosespiritualmente, à narrativa mítica, que prescinde de causalidade lógica, por ser de ordem mais afetiva que intelectual. A lírica moderna retoma a linguagem primordial como a acusar - dentro da nova percepção do mundo, imposta pela industrialização, que pulverizou o homem e o Conhecimento - o domínio do logos autocrático. Racionalidade ameaçada, a poesia contorce-se num esgar que contraria o imperialismo da análise e dos números. A sociedade endurece seus mecanismos de autodefesa através do discurso burocrático desconsiderando o gesto lírico que, para sobreviver, se encastela em terreno supostamente próprio e particular. Contudo, é conflitante o diálogo entre o desejo mítico de se fazer fantasia, desconhecendo a expressão verbal, e a palavra, definidora do real. Arriete Vilela mostra sua tentativa, em todo o texto, de resolver o impasse e, ao mesmo tempo, sua submissão ao seu instrumento de trabalho:

Tu precisas entender a fantasia da dimensão de labirinto de que emergem todos os nossos avessos. Nós nos alimentamos da força viva desse amor e, mesmo quando estou abandonada ao grotesco da palavra e tu sangras saudades e ciúmes na retina dos meus olhos, sei que me alimentas de mar e de alegria, e eu te alimento de seiva e de cores (p. 48; grifo meu).

O grande herói do texto de Arriete, que parece ser o amor, é, na verdade, a palavra: a fantasia e o seu avesso entregam-se, em todas as páginas, a uma luta de vaivéns, avanços e recuos. Todo o texto é a discussão acerca da palavra poética; pretextando falar do amor, $O$ texto fala de si mesmo - circular e autocentrado -, numa metalinguagem que procura disfarçar-se. O tempo mítico 
é, enfim, posto em xeque pelo tempo da ciência. Aliás, isso está evidenciado no próprio título do livro: Fantasia e avesso. "Fantasia", do grego phantasía, que vem de phaino, fazer brilhar, mostrar, mostrar-se, manifestar, manifestar-se, reportar-se à luz originária ("Fiat lux!"), fundadora dos tempos míticos; opõe-se-lhe "avesso", do latim adverso, literalmente o "lado mau", o lado oposto ao principal, contrário, o tempo da Cultura, depois da Queda, da desobediência, da expulsão do Paraíso, da perda da luz...

Os termos, assim, estão em franca contradição, e só a leitura dos textos é que permite confir $\neg$ mar o que, etimologicamente, já se encontra sugerido. Tempos opos $\neg$ tos. Natureza e Cultura; sensível e intelectivo; luz e sombra; fantasia e avesso.

\section{A palavra contra o desejo}

A palavra poética - que, antes mesmo de ser poética, é palavra - é o motivo da reflexão de Arriete Vilela, que, falando da paixão, subordina-a ao $\log o s$, contra o próprio desejo. Esse é o percurso do pensamento ocidental desde a instauração da filosofia na antiga paidéia grega. Nesse momento, deu-se a cisão entre logos e physis, a palavra e a coisa, a razão e a emoção, a mão e o pensamento. Os sofistas, no século $\mathrm{V}$ a. C., operaram, com a defesa da palavra, a separação entre a sensibilidade e a racionalidade. O conhecimento do mundo, que partiu da visão das coisas na natureza, gerando um sentimento de encantamento, passou a prescindir do olho físico em busca do olho espiritual, razão por que o corpo, e tudo que estivesse relacionado com ele, foram rebaixados à condição de corruptíveis e efêmeros, portanto imprestáveis para o Conhecimento das essências; por sua vez, o espírito, liberto do corpo, cumpriria sua ascese à luz divina, além da caverna.

$\mathrm{Na}$ origem, visão e conhecimento constituíam um único ato: eidós, imagem, forma, gerou idea, ideia, raciocínio. A poesia também sofreu golpes que mutilaram seu significado primordial. Fantasia e palavra tornaram-se 
igualmente distintos e separados. O olho, que percebia a luz natural, tornou-se humano, quando o homem concebeu o objeto como objeto social. Marx, a esse respeito, diz com muita propriedade:

É evidente que o olho humano goza de modo distinto que o olho bruto, não humano, que o ouvido humano goza de maneira distinta que o bruto etc. Como vimos, o homem só não se perde em seu objeto quando este se configurar como objeto humano ou homem objetivado. E isso somente será possível quando se lhe configurar como objeto social e quando ele mesmo se configurar como ser social, assim como a sociedade se configurará nesse objeto como ser para ele. (MARX, 1987, p. 177-178; os grifos são de Marx).

Quando, na Grécia antiga, se impôs uma antropologia no lugar das cosmologias e, assim, tornouse possível a atividade filosófica, visão e conhecimento se separaram (CHAUÍ, 1988). O tempo mítico cedeu ao tempo da ciência. A palavra, antes palavra-coisa, desligou-se dos objetos, que, agora tornados humanos, sociais, requerem um novo modo de olhar e sentir. E a poesia tornou-se gratuita. E perdeu-se na azáfama da modernidade. Arriete Vilela denuncia a perda da poesia original e a invasão do logos dominador:

A farpa na alma, amor. Se consigo tirá-la, posso tornar este momento intuitivo e mágico. No entanto, agora, a palavra é um instante inabitável e eu flutuo num enorme vazio, desenraizada e leve. A palavra, agora, não faz redemoinho no oco da fantasia e eu estou absoluta-mente quieta. (p. 53; grifos meus)

A palavra contra o desejo, fazendo "redemoinho no oco da fantasia”. Na dialética desejo versus palavra, parece, 
em algumas passa_gens, que a poesia se fluidifica e se torna apenas espectro, simulacro. A palavra já não consegue aprisionar a ideia: "a palavra é um instante inabitável e eu flutuo num enorme vazio, desenraizada e leve". Amor, então, sofre o dilema de ser e não ser palavra:

Eu gosto do silêncio, amor, porque a palavra às vezes é apenas um ladrilho em cuja borda quebrada eu me firo constantemente. (p. 54; grifo meu)

Nunca - como acontece na modernidade - a palavra, a despeito de ser o instrumento responsável pela ruptura com a fantasia, phaino, luz original, foi tão valorizada, a ponto de se transformar no próprio tema poético. O conceito romântico da lírica como manifestação do estado de alma do artista decai nos tempos modernos, e a poesia passa a ser, antes de tudo, linguagem. "Quando suavidades afins do sentimento querem inserir-se, palavras desarmoniosas e duras atravessam-nas como um projétil, despedaçando-as" (FRIEDRICH, 1978, p. 17): "a palavra às vezes é apenas um ladrilho em cuja borda quebrada eu me firo constantemente".

A linguagem quer ver-se a si própria qual Narciso. A poesia moderna entedia-se com a realidade e quer despir a palavra da sua condição de signo portador de uma ideologia. Antes, porém, de alojar-se no texto literário, a palavra circula no meio social, de onde se alimenta. Não é apenas som, seu lado físico, mas é também significação, que nunca é individual, mas interindividual. Por mais insólito e estranho que seja o texto literário, ele é prenhe de significados sociais, pois não prescinde das duas categorias básicas do acontecer e do existir: o espaço o o tempo. Essas categorias resolvem-se, respectivamente, no nome e no verbo, que constituem a frase, ou seja, através de duas operações, segundo Bosi (1977, p. 65): a denominação (a fantasia torna-se nome) e a predicação (algo que se diz da fantasia). Frase é duração, é permanência e também fluxo. Se poesia fosse só nome, sofreria carência de tempo. 
O tempo, nesse caso, se daria pela repetição contínua do nome, que, pronunciado inúmeras vezes, fingiria o percurso temporal. Como, então, querer que a literatura seja um discurso autônomo, se ela, para existir, se insere no espaço e no tempo da cultura?

Sendo o homem um ser cultural, é produtor de instrumentos, de ideias, de imagens; vive num tempo e num espaço definidos. $O$ ato de escrever - que é tematizado por Arriete Vilela - é, sem dúvida, um ato cultural no sentido antropológico do termo. Depurar-se, livrar-se do contingente, do ponto de vista esteticista, seria rein $\neg$ ventar uma nova linguagem. Por sinal, Arriete parece ter cogitado dessa aventura:

Sim, a palavra, amor; pérola na ostra pistilo, larva e lastro, possibilidade e intuição. Uma estranheza que, às vezes, apesar da dor, na carne, paira muito além de mim. A palavra: uma re/invenção, um sufrágio, um acúmulo. Uma perplexidade, quase sempre. O que excede da minha paixão, hemorrágica e vadia (p. 21; grifos meus).

A palavra é o ser que dá nome à fantasia, introduzindo-a no mundo humano, das relações sociais. $\mathrm{Da}$ palavra-amor (conhecimento-visão) chegou-se ao amor da palavra: do desejo à linguagem; da linguagem ao desejo. Palavra contra o desejo; palavra: sublimação e redução da paixão. 


\section{Referências}

BAKHTIN, Mikhail. Marxismo e filosofia da linguagem:

problemas fundamentais do método sociológico na ciência da lin`guagem. 2. ed. São Paulo: Hucitec, 1981.

BOSI, Alfredo. O ser e o tempo da poesia. São Paulo: Cultrix;

Ed. da Universidade de São Paulo, 1977.

CHAUI, Marilena. Janela da alma, espelho do mundo. In:

NOVAES, Adauto (Org.). O olhar. São Paulo: Companhia das Letras, 1988. p. 31-63.

FRIEDRICH, Hugo. Estrutura da lírica moderna: da metade do século XIX a meados do século XX. São Paulo: Duas Cidades, 1978.

MARX, Karl. Manuscritos econômico-filosóficos e outros textos escolhidos. 4. ed. São Paulo: Nova Cultural, 1987. (Os Pensadores).

NOVAES, Adauto. De olhos vendados. In: (Org.). O olhar. São Paulo: Companhia das Letras, 1988. p. 9-20.

THOMSON, George. Marxismo e poesia. Lisboa: Editorial Teorema, 1977.

VILELA, Arriete. Fantasia e avesso. Maceió: Secretaria de Cultura; Sergasa, 1986. 